\title{
Application of Firefly Algorithm for Optimal Directional Overcurrent Relays Coordination in the Presence of IFCL
}

\author{
Rabah Benabid \\ Department of Electrical Engineering, CRNB, Djelfa, Algeria \\ E-mail:rabah_benbid@yahoo.fr \\ Mohamed Zellagui, Abdelaziz Chaghi \\ LSP-IE, Department of Electrical Engineering, University of Batna, Algeria \\ E-mail:m.zellagui@ymail.com,az_chaghi@univ-batna.dz
}

\begin{abstract}
Mohamed Boudour
LSEI, Department of Electrical Engineering, University of Sciences and Technology Houari Boumediene, Algeria E-mail: mboudour@ieee.org
\end{abstract}

\begin{abstract}
This paper considers the impact of the Inductive Fault Current Limiter (IFCL) on directional overcurrent relays coordination. The coordination problem is formulated as a non-linear constrained mono-objective optimization problem. The objective function of this optimization problem is the minimization of the operation time of the associated relays in the systems, and the decision variables are: the time dial setting $(T D S)$ and the pickup current setting $\left(I_{P}\right)$ of each relay. To solve this complex non linear optimization problem, a variant of optimization algorith ms named Firefly Algorithm (FA) is used. The proposed method is tested on 8-bus power transmission systems test systems considering the influences of current relay under three-phases short-circuit with and without IFCL for different locality. The results show the effectiveness of the solution.
\end{abstract}

Index Terms - Inductive Fault Current Limiter, Fault Current, Directional Overcurrent Relay, Optimal Coordination Time, Setting Relay, Firefly Algorithm

\section{Introduction}

As an electrical power system continues to expand in size, generation capacity and transmission network expansion may be restricted by the fault current limit. Such restrictions on generation capacity and transmission network can particularly affect the reliabilities of the power system adversely [1, 2]. Therefore, to deal with the fault problem, an approach to limit the value of fault currents when a short circu it takes place seems more desirable. The reliability and efficiency of the fault current limiting approach must be emphasized. Today, options available for utility companies to reduce fault currents of a power grid are not many. More unfortunate, there are some significant drawbacks for this small number of options. For instance, using high impedance transformers and earthing reactors will compromise the efficiency and increase the cost of the power system. Another option is to split existing networks, which allows fault currents to be reduced, but to the detriment of the stability and efficiency of the grid [3]. A fault current limiter (FCL) is one of the promising fault current limiting technologies that are expected to find greater use for limiting fault currents in power systems in the near future. A FCL is a device placed in electric network to limit the peak fault current. Basically, the FCL is variable impedance that is installed in series with a circuit breaker. In case of a fault, the impedance rises to a value at which the fault current is correspondingly reduced to a lower level that the circuit breaker can cope with $[4,5]$. The FCL can offer cost-effective means to limit the high level fault currents to lower levels which allow circuit breakers contact to open quickly and safely. Application of the FCL in electric power systems is expected not only to suppress the amplitudes of the fault currents but also to enhance the power systemstability and quality [6].

To insure reliability of the protective system, the back-up scheme shouldn't come in to action unless the primary fails to take the appropriate action. In other words, it should operate after a certain time delay known as coordination time interval (CTI), giving the chance for the primary protection to operate. The fore mentioned situation leads to the formu lation of the wellknown protective relay setting coordination, that consists of the selection of a suitable setting of each relay such that their fundamental protective function is 
met under the desirable qualities of protective relaying, namely sensitivity, selectivity, reliability, and speed [7].

In recent years, many research efforts have been made to achieve optimum protection coordination (optimum solution for relay settings) without SC using different techniques and methodologies, including Interval Linear Programming (ILP) in [8], and Nonlinear Programming (NLP) techniques environment by Sequential Quadratic Programming (SQP) method in [9], and as well as the Simplex Method (SM) in [10] and Two Phase Simplex Method (TPSM) in [11]. However a new objective function approach is presented to solve the optimization problem of coordination with the Continuous Genetic Algorithm (CGA) in [12], Evolutionary Algorithms (EA) is presented in [13], Seeker Algorithm (SA) is presented in [14], and Teaching Learning-Based Optimization (TLBO) in [15].

In this paper we present the solution of the coordination problem of directional overcurrent relays using firefly algorithm in the presence IFLC for minimized short-circuit current. This optimization is used to find an optimal setting of Time $T D S$ and $I_{p}$ of each relay that minimizes the operating time of overall relays. The new idea presented in this paper is taking into account the variation of the effective impedance of the line caused by the action of IFCL devices. Three simulation scenarios are considered in this paper, one without IFCL and two considering the location of IFCL devices.

\section{Inductive Fault Current Limiter}

An FCL is a variable-impedance device that is connected in series with a power circuit to limit the system current under fault conditions. It has low impedance (ideally negligible impedance) under normal operating conditions and high impedance (not infinite) under fault conditions. Many kinds of FCLs have been developed over the past several decades [16]. These can be classified into three main groups depending on their fundamental technology: 1) superconducting FCLs [5, 6], [17], magnetic FCLs [18], and solid-state FCLs [19]. Alternatively, classification by impedance is possible, in which case the main classes are inductive FCLs and resistive FCLs. Due to less heat dissipation and lower requirements on cooling systems, we have considered only inductive FCLs, not resistive FCLs, in this paper.

In order to investigate the influence of IFCLs on system performance, a "physics-independent" dynamic model is developed here. It should be noted that this physics independent model and the related analysis in this paper are suitable for the inductive fault current limiters which have linearly-changing inductance within a certain time, not for the devices with non-linearly changing-inductance devices.

The IFCL is modeled as a changing-inductance device with its control logic, to reflect the external dynamic performance in electric power systems. The model can be used to analyze system performance of a wide range of implementations of inductive FCLs by changing the model parameters, such as maximum impedance, minimum impedance, activation time, and recovery time. The IFCL model is connected in series with one control circuit to decide its inductance. The control signal initiates an irrevocable change in the device's inductance which has two steady state values: $L_{\min }$ and $L_{\max }$. After a transition is commanded, $L$ changes continuously from one of these limits to the other, along a trajectory that can have several mathematical forms.

The four user-adjustable parameters of this model are: activation time $\left(\tau_{\text {increase }}\right)$ recovery time $\left(\tau_{\text {decrease }}\right)$, minimum inductance $\left(L_{m i n}\right)$ and maximum inductance $\left(L_{\text {max }}\right)$, as shown in figure 1 . The system voltage crosses zero at point $A$, a fault occurs at point $B$, and an FCL is triggered and its inductance starts to increase at point $C$ [20].

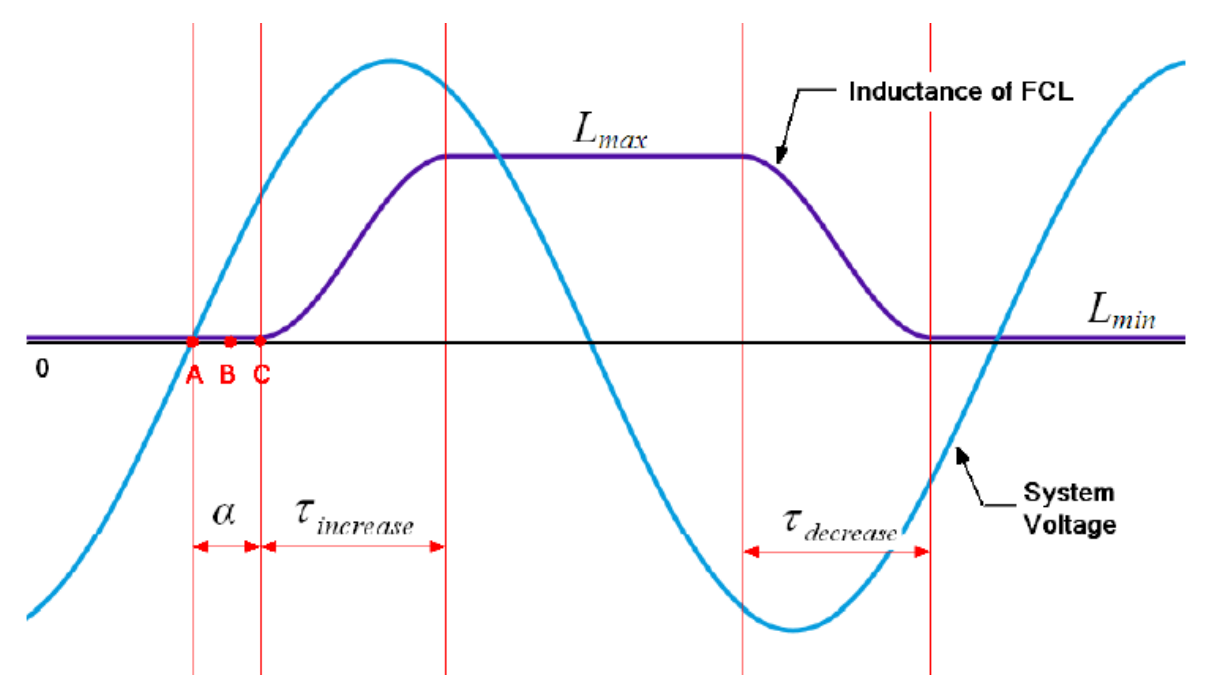

Fig. 1: Changing inductance of inductive FCL and system voltage 
Consider the circuit shown in Figure 2, the inductive FCL to be tested is placed in series with the load and immed iately after the main substation (circuit-breaker). A bolted three phase to ground fault is inserted right at the terminals of the FCL for $500 \mathrm{~ms}$ with a fault resistance $\left(R_{F}\right)$ is the $10 \Omega$.

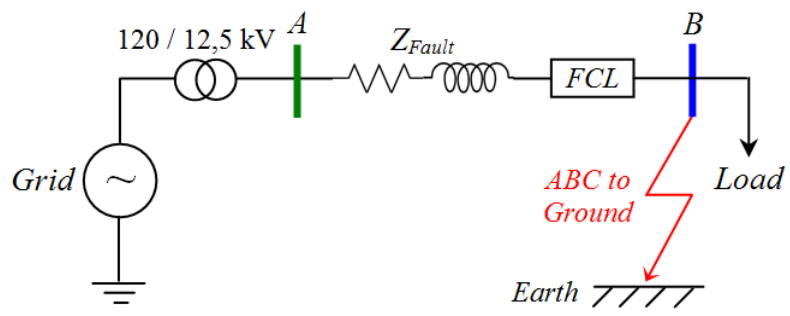

Fig. 2: A typical radial distribution system used for IFCL simulation

Figure 3 is show the current waveform and RMS with and without FCL respectively. We note that by inserting the IFCL with an $L_{\max }=0,23 \mathrm{mH}$ for a voltage $12,5 \mathrm{kV}$ and 5,8 MVA system the current can be limited by at least $18,73 \%$ to $16 \mathrm{kA} \mathrm{rms}$.

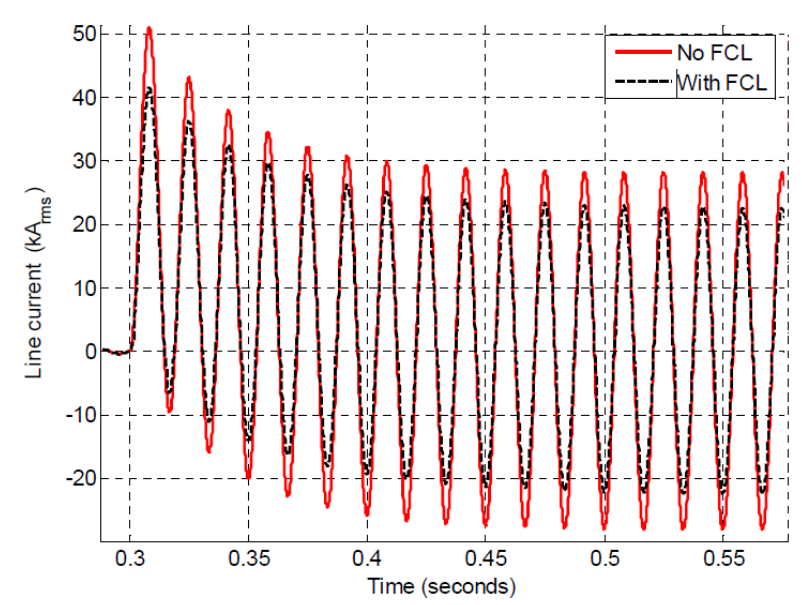

(a)

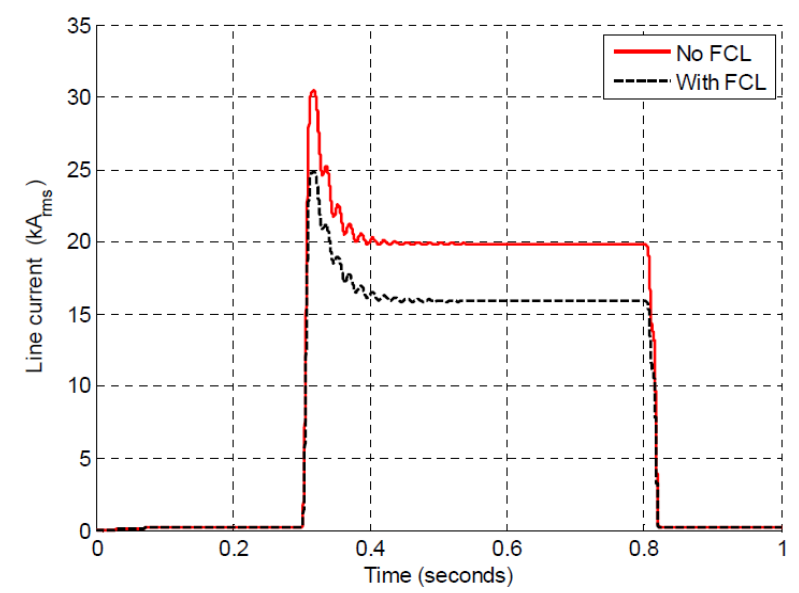

(b)

Fig. 3: Phase $A$ current for with/without IFCL. a). Current waveform, b). Current RMS
By varying the inductance of the IFCL, a better current limitation can be achieved. From simulation studies, a linear relationship exists between the value of IFCL impedance and how much current is limited. Also, we observe that the time constant is about 9 cycles after the steady state faulted current is achieved.

\section{Optimal Overcurrent Relay Coordination}

The coordination of IDMT directional overcurrent relays in a multi-loop system is formulated as an optimization problem. The coordination problem, including objective function and constraints, should satisfy three requirements.

\subsection{Objective Function}

The aim of this function $(f)$ is to minimize the total operating time of all overcurrent protection relays in the system with respect to the coordination time constraint between the backup and primary relays.

$$
f=\operatorname{Min}\left\{\sum_{i=1}^{N} T_{i}\right\}
$$

Where, $T_{i}$ represents the operating time of the $i^{\text {th }}$ relay, $N$ represents the number of relays in the power system. For each protective relay the operating time $T$ is defined as follows [10-15]:

$$
T_{i}=T D S \times \frac{K}{\left(I_{M} / I_{P}\right)^{S}+L}
$$

Where, $T$ is relay operating time ( $s e c$ ), $T D S$ is time dial setting (sec), $I_{M}$ is the fault current measured by relay $(A), I_{P}$ is pickup current $(A), K_{C T}$ is ratio of the current transformer. The constant $K, L$, and $S$ depend on the characteristic curve for IDMT directional overcurrent relay. The current $I_{M}$ is defined by:

$$
I_{M}=\frac{I_{F}}{K_{C T}}
$$

\subsection{Constraints}

The coordination problem has two types of constraints, including the constraints of the relay characteristic and coordination constraints. Relay constraints include limits of relay operating time and settings. Coordination constraints are related to the coordination of primary and backup relays. 


\subsubsection{Relay Operating Time}

The operating time of a relay is a function of the pickup current setting and the fault current seen by the relay. Based on the type of relay, the operating time is determined via standard characteristic curves or analytic formula. The bounds on operating time are expressed by:

$$
T_{i}^{\min } \leq T_{i} \leq T_{i}^{\max }
$$

Where, $T_{i}^{\min }$ and $T_{i}^{\max }$ are the minimu $\mathrm{m}$ and maximu $\mathrm{m}$ operating times of the $i^{\text {th }}$ overcurrent relay.

\subsubsection{Coordination Time Interval}

During the optimization procedure, the coordination between the primary and the backup relays must be verified. In this paper, the chronometric coordination between the primary and the backup relays is used as follows equation:

$$
T_{\text {backup }}-T_{\text {primary }} \geq C T I
$$

Where, $T_{\text {backup }}$ and $T_{\text {primary }}$ are the operating time of the backup relay and the primary relay respectively, $C T I$ is the minimum coordination time interval. For the electromechanical relays, the $C T I$ is varied between 0.30 to $0.40 \mathrm{sec}$, while for the numerical relays it's varied between 0.10 to $0.20 \mathrm{sec}[14,15]$.

\subsection{Time Dial and Pickup Current Settings}

The time dial setting (TDS) adjusts the time delay before the relay operates when the fault current reaches a value equal to, or greater than, the pickup current $\left(I_{P}\right)$ setting [12-15].

$$
\begin{aligned}
& T D S_{i}^{\min } \leq T D S_{i} \leq T D S_{i}^{\max } \\
& I_{P i}^{\min } \leq I_{P i} \leq I_{P i}^{\max }
\end{aligned}
$$

Where, $T D S_{i}^{\min }$ and $T D S_{i}^{\max }$ are the minimum and the maximum limits of $T D S$ for the $i^{\text {th }}$ relay. $I_{P i}^{\min }$ and $I_{P i}^{\max }$ are the minimum and the maximum limits of $I_{P}$ for the $i^{\text {th }}$ relay.

\section{Firefly Optimization Algorithm}

Nature-inspired methodologies are among the most powerful algorithms for optimization problems. The Firefly Algorithm (FA) is a novel nature-inspired algorithm inspired by the social behavior of fireflies, was induced by Yang in 2008 [21, 22].
The algorith m was based on the idealized behavior of the flashing characteristics of fireflies. Although FA has many similarities with other algorithms which are based on the so-called swarm intelligence; it is indeed much simpler both in concept and implementation [2123]. Furthermore, this proposed technique is very efficient and can outperform other conventional algorithms, for solving many optimization problems; where the statistical performance of the firefly algorithm was measured against other well-known optimization algorithms using various standard stochastic test functions [21]. The pseudo code of the firefly-inspired algorithm was developed using these three idealized rules [21-23]:

1). All fireflies are unisex and are attracted to other fireflies regardless of their sex,

2). The degree of the attractiveness of a firefly is proportional to its brightness, and thus for any two flashing fireflies, the one that is less bright will move towards the brighter one. More brightness means less distance between two fireflies. However, if any two flashing fireflies have the same brightness, then they move randomly,

3). Finally, the brightness of a firefly is determined by the value of the objective function. For a maximization proble $\mathrm{m}$, the brightness of each fire fly is proportional to the value of the objective function and vice versa.

As light intensity and thus attractiveness decreases as the distance from the source increases, the variations of light intensity and attractiveness should be monotonically decreasing functions. In most applications, the combined effect of both the inverse square law and absorption can be approximated using the following Gaussian form:

$$
I(r)=I_{0} e^{-\gamma \cdot r^{2}}
$$

Where, $r$ is the distance between any two fireflies, $I_{0}$ is the original light intensity and $\gamma$ is the light absorption coefficient which controls the decrease of light intensity and can be taken as a constant. As a firefly's attractiveness is proportional to the light intensity seen by adjacent fireflies.

\subsection{Degree of the Attractiveness of a Firefly}

In the FA, the main form of attractiveness function $\beta$ can be any of the monotonically decreasing functions as given in:

$$
\beta(r)=\beta_{0} e^{-\gamma \cdot r_{p q}^{n}} n \geq 1
$$

Where, $\beta_{0}$ is the attractiveness at $r=0$ [24] and also the movement of a firefly $(i)$ is attracted to another more attractive (brighter) firefly $(j)$. 


\subsection{Distance}

The attractiveness can be achieved by tuning the parameters $\beta_{0}$ and $\gamma$. The distance $r_{i j}$ between two fireflies is given in [22]:

$$
r_{i j}=\left\|x_{i}-x_{j}\right\|=\sqrt{\sum_{k=1}^{d}\left(x_{i, k}-x_{j, k}\right)^{2}}
$$

Where, $x_{i, k}$ is the $k^{\text {th }}$ component of the spatial coordinate of the $j^{\text {th }}$ firefly and $d$ is the number of dimensions. The $j \in\{1,2, \ldots, m\}$ is a randomly chosen index. Although $j$ is determined randomly, it has to be different from $i$. Here, $m$ is the number of fireflies. For other applications such as scheduling, the distance can be any of the suitable forms, and not necessarily the Cartesian distance (equation 10).

In general, $\beta_{0} \in[0,1]$, and this when $\beta_{0}=0$, only a non-cooperative distributed random search is applied. When $\beta_{0}=1$, the scheme of a cooperative local search is performed such that the brightest firefly strongly determines the other fireflies' position, especially in its neighborhood [21, 22]. When $\gamma=0$, there is no variation or the fire flies have constant attractiveness. When $\gamma=\infty$, it results in attractiveness being close to zero, which again is equivalent to the complete random search. In general, the value of $\gamma$ is between 0 and 10 [21, 22], which guarantees a quick convergence of the algorithm to the optimal solution.

\subsection{Movement}

The movement of a firefly $i$, when attracted to another more attractive (brighter) firefly $j$, is determined by [22]:

$$
x_{i}^{\prime}=x_{i}+\beta(r) \times\left(x_{i}-x_{j}\right)+\alpha\left(\operatorname{rand}-\frac{1}{2}\right)
$$

Where, $x_{i}^{\prime}$ is the firefly position of the next generation. $x_{i}$ and $x_{j}$ are the current position of the fireflies and $x_{i}^{\prime}$ is the $i^{t h}$ firefly position of the next generation. The second term in equation 15 is due to attraction. The third term introduces randomization, with $\alpha$ being the randomization parameter and "rand" is a random number generated uniformly but distributed between 0 and 1 . The convergence of the algorith $m$ is obtained when $m \geq n$ for any large number of fireflies $(m)$, where $n$ is the number of local optima of an optimization problem [21].

\section{Case Study and Simylation Resultas}

The proposed optimization algorith $\mathrm{m}$ is validated and tested on IEEE 8 bus transmission test system that has two power sources, seven lines and 14 relays. For each case, the following three scenarios are considered:
Scenario $A(S C A)$ : optimal relays coordination without IFCL.

Scenario B (SC B): optimal relays coordination with IFCL installed at midline line between bus 1 and 6 .

Scenario $C(S C \quad C)$ : optimal relays coordination considering IFCL installed at mid line line between bus 1 and 6, and after two power source (G.1 and G.2).

As we mentioned before, the line series compensation will modify the effective impedance of the line as well as the short circuit current seen by the relays. For this reasons, the three phase short circuit currents are developed and computed for each simulation scenario.

In the three scenarios $A, B$ and $C$, the CTI is fixed to 0,20 second and the TDS is limited $(0.1 \leq T D S \leq 1.1)$ and $I_{p}$ is limited $\left(0.5 \leq I_{p} \leq 2.5\right)$. Furthermore, the numerical overcurrent relays characteristic is considered as normal inverse according to the IEC standard and for the IDMT directional overcurrent relays, the constant $K$, $L$, and $S$ are defined as follows: $K=0.14, S=0.02$, and $L=-1$.

Figure 4, represents the second case study of a transmission network fed by two generators and with six bus, seventh lines and fourth load. The power system study is compensated with IFCL located at middle of the transmission line 1-6 and two IFCL for power sources (G.1 and G.2) as well. The 8-bus system has a link to another network, modelled by a short circuit power of $400 \mathrm{MVA}$. The transmission network consists of 14 numerical DOCRs relays [14].

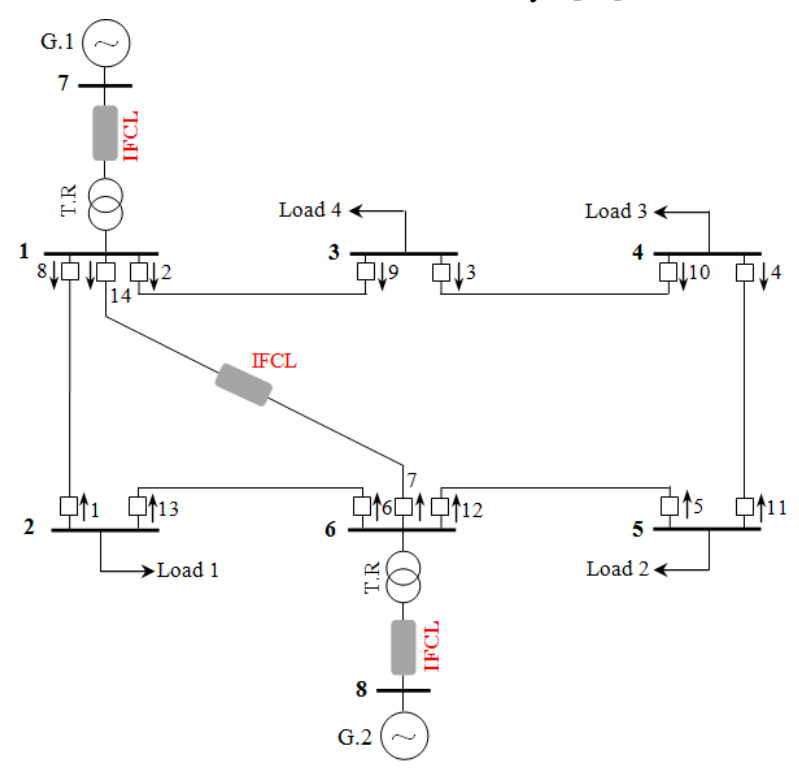

Fig. 4: Diagram of the 8-bus transmission study with IFCL

\subsection{Impact IFCL on Fault Current}

Figure 5 presents the impact of IFCL on the fault current values. From this figure, it is well shown that the IFCL reduces the fault current seen by the relays that confirms the main purpose of this device. 
Furthermore, we can observe also, that the placement of the IFLC in the power system has a great influence on its efficiency. The fault current is well reduced in SC C compared with SC B. From these results, we can conclude that the placement of the IFLC in the power systemmust be chosen wisely.

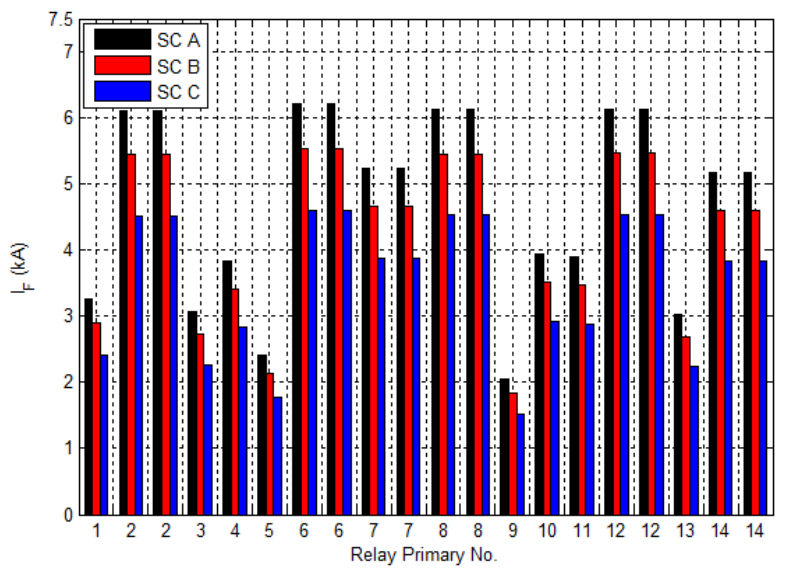

(a)

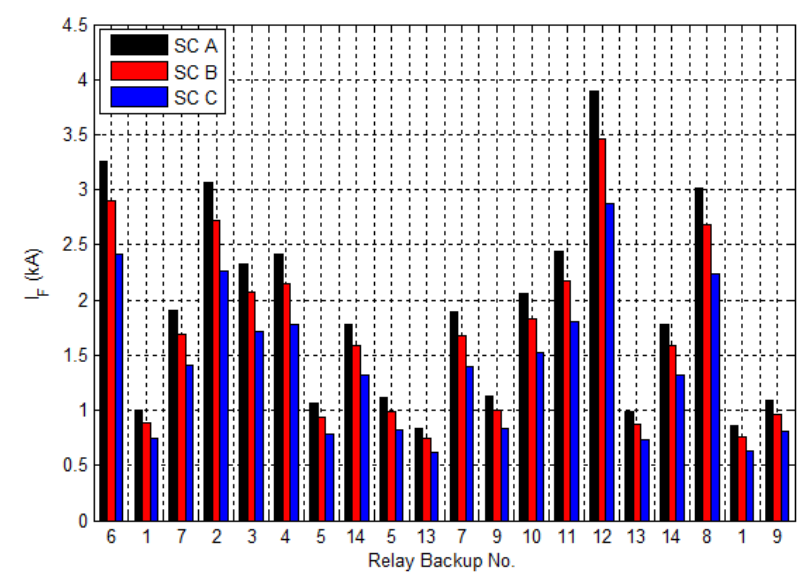

(b)

Fig. 5: Fault current for all scenarios

a). Primary relays, b).Backup relays

\subsection{Impact of IFCL on CTI}

In order to show the impact of IFCL on the directional overcurrent relays coordination, we use the following relays setting presented in table 1 . The convergence characteristics of the FA for the scenarios SC A (without IFCL) are depicted in figure 6.

Table 2 presents, the CTI with and without IFCL. From this table we can see the relays are well coordinated in scenario SC A. Unfortunately we remark that the pairs of the overcurrent relays (5 and 4) are not coordinated for the two scenarios SC B and SC C (as shown in bold).

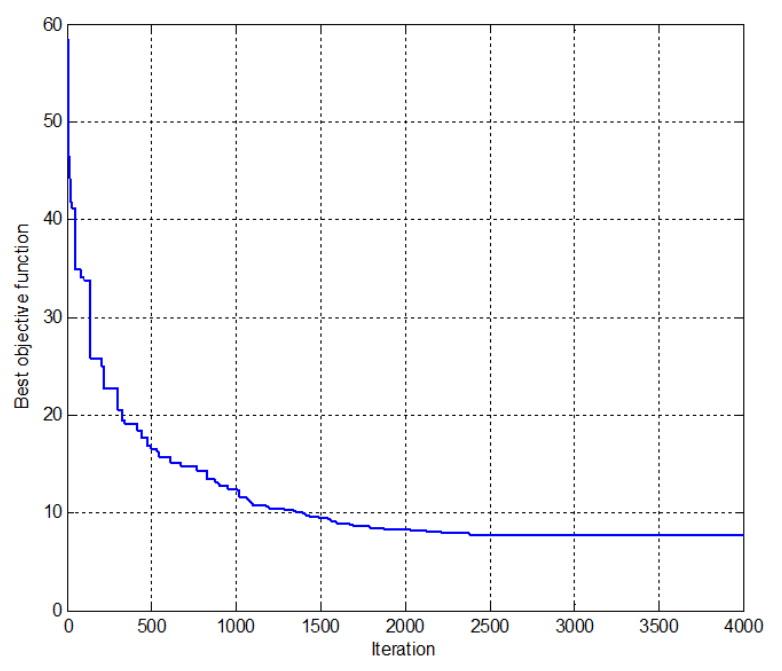

Fig. 6: Convergence characteristic of FA for SC A

Table 1: Optimal relays coordination solution for SC A

\begin{tabular}{|c|c|c|}
\hline \multirow{2}{*}{ IDMT Relay No. } & \multicolumn{2}{|c|}{ Control variables } \\
\hline & $T D S$ & $I_{P}$ \\
\hline 1 & 0.1000 & 1.8307 \\
\hline 2 & 0.2455 & 1.7843 \\
\hline 3 & 0.2247 & 1.8407 \\
\hline 4 & 0.2282 & 0.9286 \\
\hline 5 & 0.1000 & 2.2071 \\
\hline 6 & 0.1542 & 1.9299 \\
\hline 7 & 0.2220 & 1.9113 \\
\hline 8 & 0.3393 & 0.6784 \\
\hline 9 & 0.2139 & 1.2261 \\
\hline 10 & 0.1533 & 2.3653 \\
\hline 11 & 0.2344 & 1.1702 \\
\hline 12 & 0.3789 & 0.7010 \\
\hline 13 & 0.1075 & 1.8142 \\
\hline 14 & 0.3630 & 0.7889 \\
\hline$f(\sec )$ & \multicolumn{2}{|c|}{7.7207} \\
\hline
\end{tabular}

From these results we can conclude that the installation of IFCL in the power system has a great impact of the CTI and thus a new setting of the relays is required. 
Table 2: Impact of IFCL on CT I value

\begin{tabular}{|c|c|c|c|c|}
\hline \multirow{2}{*}{$\begin{array}{c}\text { Primary } \\
\text { Relay }\end{array}$} & \multirow{2}{*}{$\begin{array}{c}\text { Backup } \\
\text { Relay }\end{array}$} & \multicolumn{3}{|c|}{ CTI value (sec) } \\
\cline { 3 - 5 } & SC A & SC B & SC C \\
\hline 1 & 6 & 0.2001 & 0.2137 & 0.2393 \\
\hline 2 & 1 & 0.2138 & 0.3241 & 0.6204 \\
\hline 2 & 7 & 0.2060 & 0.2343 & 0.2913 \\
\hline 3 & 2 & 0.2005 & 0.2204 & 0.2594 \\
\hline 4 & 3 & 0.2000 & 0.2216 & 0.2634 \\
\hline 5 & 4 & 0.2000 & $\mathbf{0 . 1 9 6 0}$ & $\mathbf{0 . 1 8 2 5}$ \\
\hline 6 & 5 & 0.5971 & 0.7822 & 1.3188 \\
\hline 6 & 14 & 0.5300 & 0.5548 & 0.5988 \\
\hline 7 & 5 & 0.4049 & 0.5569 & 0.9847 \\
\hline 7 & 13 & 0.6187 & 0.8493 & 1.5551 \\
\hline 8 & 7 & 0.2068 & 0.2435 & 0.3164 \\
\hline 8 & 9 & 0.2109 & 0.2505 & 0.3302 \\
\hline 9 & 10 & 0.2001 & 0.2497 & 0.3605 \\
\hline 10 & 11 & 0.2004 & 0.2083 & 0.2215 \\
\hline 11 & 12 & 0.2101 & 0.2137 & 0.2189 \\
\hline 12 & 13 & 0.2001 & 0.3283 & 0.6670 \\
\hline 12 & 14 & 0.2239 & 0.2435 & 0.2799 \\
\hline 13 & 8 & 0.4085 & 0.4174 & 0.4304 \\
\hline 14 & 1 & 0.3815 & 0.5798 & 1.1821 \\
\hline 14 & 9 & 0.2002 & 0.2421 & 0.3267 \\
\hline & & & & \\
\hline
\end{tabular}

\subsection{Optimal New Setting and Coordination}

To overcome the Lack of the CTI resulted by the insertion of the IFCL in the power system, we propose the formulation of this problem as a constrained monoobjective problem and solve it using the FA. The convergence characteristics of the method for the scenarios SC B and SC C are depicted in figures 7.a and 7.b respectively. The new relays setting for two scenarios SC B and SC C are presented in table 3 and 4 respectively. From this table, we can notice that the FA provides different relays setting of each scenario.

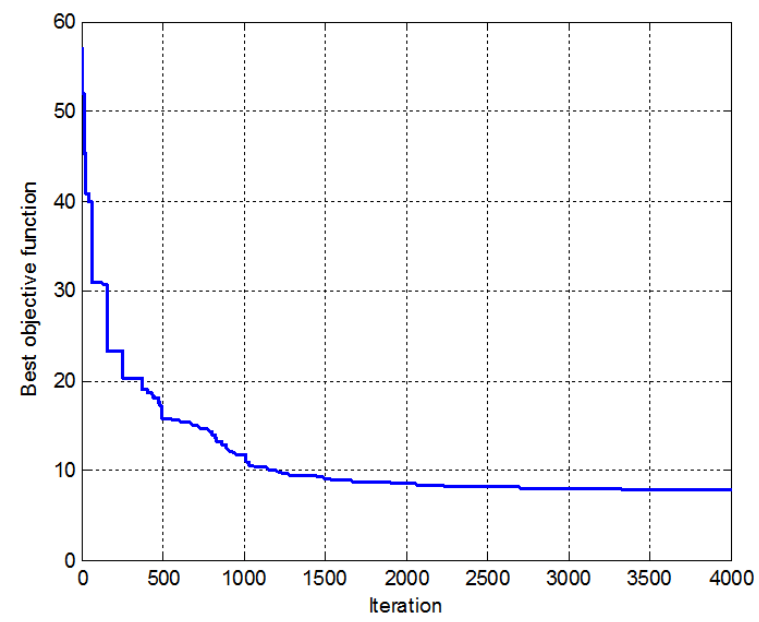

(a)

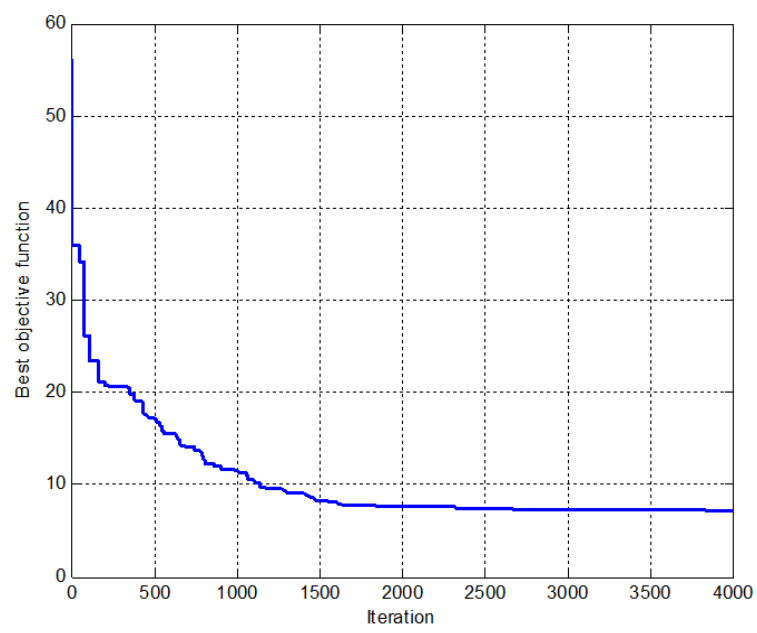

(b)

Fig. 7: Convergence characteristics of the FA with IFCL. a). SC B, b). SC C.

Table 3: Optimal relays coordination solution for SC B

\begin{tabular}{|c|c|c|}
\hline \multirow{2}{*}{ IDMT Relay No. } & \multicolumn{2}{|c|}{ Control variables } \\
\hline & $T D S$ & $I_{P}$ \\
\hline 1 & 0.1000 & 1.6403 \\
\hline 2 & 0.2372 & 1.5395 \\
\hline 3 & 0.1907 & 2.0280 \\
\hline 4 & 0.1681 & 1.4742 \\
\hline 5 & 0.1000 & 1.8731 \\
\hline 6 & 0.1445 & 1.9437 \\
\hline 7 & 0.2209 & 1.6985 \\
\hline 8 & 0.1892 & 1.3738 \\
\hline 9 & 0.3026 & 0.6438 \\
\hline 10 & 0.1591 & 2.2950 \\
\hline 11 & 0.2156 & 1.4324 \\
\hline 12 & 0.5075 & 0.5877 \\
\hline 13 & 0.1082 & 1.8887 \\
\hline 14 & 0.2881 & 1.7714 \\
\hline$f(\sec )$ & \multicolumn{2}{|c|}{7.8948} \\
\hline
\end{tabular}


Table 4: Optimal relays coordination solution for SC C

\begin{tabular}{|c|c|c|}
\hline \multirow{2}{*}{ IDMT Relay No. } & \multicolumn{2}{|c|}{ Control variables } \\
\hline & $T D S$ & $I_{P}$ \\
\hline 1 & 0.1000 & 1.2675 \\
\hline 2 & 0.1667 & 2.1464 \\
\hline 3 & 0.1712 & 1.8483 \\
\hline 4 & 0.1532 & 1.2595 \\
\hline 5 & 0.1000 & 1.2943 \\
\hline 6 & 0.1288 & 1.8942 \\
\hline 7 & 0.1476 & 2.1755 \\
\hline 8 & 0.1695 & 1.4703 \\
\hline 9 & 0.2875 & 0.5038 \\
\hline 10 & 0.1333 & 2.1839 \\
\hline 11 & 0.1972 & 1.1872 \\
\hline 12 & 0.3299 & 1.2556 \\
\hline 13 & 0.1000 & 1.8821 \\
\hline 14 & 0.2743 & 1.3448 \\
\hline$f(\mathrm{sec})$ & \multicolumn{2}{|c|}{7.2369} \\
\hline
\end{tabular}

The new CTI values of scenarios SC B and SC C (in the presence IFCL) after optimization using FA are presented in table 5. From th is table, we can see that all primary and backup relays are well coordinated for all scenarios. These results indicate that the FA method has a great capability to solve this complex optimization problem and provides a new protection relays setting that ensure the relay coordination for various installation scenarios of the IFCL.

Table 5: New CTI value of SC B and SC C after optimization

\begin{tabular}{|c|c|c|c|}
\hline \multirow{2}{*}{$\begin{array}{c}\text { Primary } \\
\text { Relay }\end{array}$} & \multirow{2}{*}{$\begin{array}{c}\text { Backup } \\
\text { Relay }\end{array}$} & \multicolumn{2}{|c|}{ CTI $($ sec $)$} \\
\cline { 3 - 4 } & SC B & SC C \\
\hline 1 & 6 & 0.2001 & 0.2004 \\
\hline 2 & 1 & 0.2492 & 0.2536 \\
\hline 2 & 7 & 0.2298 & 0.2041 \\
\hline 3 & 2 & 0.2003 & 0.2000 \\
\hline 4 & 3 & 0.2001 & 0.2002 \\
\hline 5 & 4 & 0.2001 & 0.2001 \\
\hline 6 & 5 & 0.5388 & 0.3684 \\
\hline 6 & 14 & 0.7528 & 0.6601 \\
\hline 7 & 5 & 0.3506 & 0.2928 \\
\hline 7 & 13 & 1.0004 & 1.8198 \\
\hline 8 & 7 & 0.3743 & 0.2796 \\
\hline 8 & 9 & 0.4512 & 0.3891 \\
\hline 9 & 10 & 0.2005 & 0.2001 \\
\hline 10 & 11 & 0.2139 & 0.2004 \\
\hline 11 & 12 & 0.4363 & 0.4170 \\
\hline 12 & 13 & 0.2000 & 0.6194 \\
\hline 12 & 14 & 0.2157 & 0.2126 \\
\hline 13 & 8 & 0.2001 & 0.2000 \\
\hline 14 & 1 & 0.3473 & 0.2981 \\
\hline 14 & 9 & 0.2212 & 0.2069 \\
\hline & & & \\
\hline
\end{tabular}

\section{Conclusion}

This paper presents an optimal setting and coordination of the overcurrent relays in the presence of IFCL device. The obtained results show that this device effectively reduces the fault current and therefore protects the different power systems components. We are concluding also, that the placement of the IFCL devices in power system has a great impact on its efficiency.

In term of relay coordination, it is well shown that the IFCL engender a miss of coordination of the relays. To overcome this technical problem, we propose the formulation of this problem as a constrained monoobjective optimization problem and solve it using the firefly optimization algorithm. The new obtained settings provide a well relays coordination in the presence of IFLC devices.

\section{References}

[1] N. Nimpitiwan, G.T. Heydt, R. Ayyanar, and S. Suryanarayanan, Fault Current Contribution from Synchronous Machine and Inverter based Distributed Generators, IEEE Transactions on Power Delivery, 2007, 22(1): 634 641,

[2] M. Guk-Hyun, L. Jaehee, and J. Sung-Kwan, Integrated Generation Capacity and Transmission Network Expansion Planning with Superconducting Fault Current Limiter (SFCL), IEEE Transactions on Applied Superconductivity, 2013, 23(3): 1 6.

[3] Ying Xin, Weizhi Gong, and all., Development of Superconducting Fault Current Limiters, International Conference on Power System Technology (PowerCon), Chongqing - China, 2226 October 2006.

[4] M. Steurer, K. Frohlich, W. Holaus, and K. Kaltenegger, "A Novel Hybrid Current Limiting Circuit Breaker for Medium Voltage: Principles and Test Results", IEEE Transactions on Power Delivery, 2003, 18(2): 946 949.

[5] L. Ye, and A. Campbell, Case Study of HTS Resistive Superconducting Fault Current Limiter in Electrical Distribution Systems, Electric Power Systems Research, 2007, 77: 534 439.

[6] Y. Shirai, et al., A Model Experiment of Current Limiting Characteristics of Superconducting Fault Current Limiter in the Demand Side with Distributed Generation, $7^{\text {th }}$ European Conference on Applied Superconductivity (EUCAS), Vienna Austria, 11-15 September 2005.

[7] P.M. Anderson, Power System Protection, published by McGraw-Hill, New York, USA, 1999.

[8] A.S. Noghabi, H.R. Mashhadi \& J. Sadeh, Optimal Coordination of Directional Overcurrent Relays 
Considering Different Network Topologies using Interval Linear Programming, IEEE Transactions on Power Delivery, 2010, 25(3): 1348 1354.

[9] D. Birla, R.P. Maheshwari \& H.O. Gupta, A New Nonlinear Directional Overcurrent Relay Coordination Technique, and Banes and Boons of Near-End Faults Based Approach, IEEE Transactions on Power Delivery, 2006, 21(3): 1176 1182.

[10] A.S. Braga \& J.T. Saraiva, Coordination of Directional Overcurrent Relays in Meshed Networks using the Simplex Method, IEEE Mediterranean on Electrotechnical Conference (MELECON), Bari, Italy, 13-16 May, 1996.

[11] P.P. Bedekar, S.R. Bhide \& V.S. Kale, Optimum Time Coordination of Overcurrent Relays using Two Phase Simplex Method, World Academy of Science, Engineering and Technology, 2009, 28: 1110 1114.

[12] P.P. Bedekar \& S.R. Bhide, Optimum Coordination of Overcurrent Relay Timing using Continuous Genetic Algorithm, Expert Systems with Applications, Elsevier, 2011, 38: 11286 11292.

[13] J.A. Sueiro, E. Diaz-Dorado, E. Míguez \& J. Cidrás, Coordination of Directional Overcurrent Relay using Evolutionary Algorithm and Linear Programming, International Journal of Electrical Power and Energy Systems, 2012, 42: 299 305.

[14] T. Amraee, Coordination of Directional Overcurrent Relays Using Seeker Algorith m, IEEE Transactions on Power Delivery, 2012, 27(3): $1415 \sim 1422$.

[15] M. Singh, B.K. Panigrahi \& A.R. Abhyankar, Optimal Coordination of Directional Overcurrent Relays using Teaching Learning-Based Optimization (TLBO) Algorithm, International Journal of Electrical Power and Energy Systems, 2013, 50: 33 41.

[16] N.K. Fall and B. Marchionini, Fault Current Limiter - R\&D Status and Testing Issues, IEEE/PES Power Systems Conference and Exposition, Seattle, 15-18 March 2009.

[17] L. Sung-Hun, K. Jin-Seok, and K. Jae-Chul, Study on Correction of Protective Devices for Application of a SFCL in a Power Distribution System with a Dispersed Generation, IEEE Transactions on Applied Superconductivity, 2013, 23(3): $1 \sim 8$.

[18] J.L. Rasolonjanahary, J. Sturgess, and E. Chong, Design and Construction of a Magnetic Fault Current Limiter, UK Magnetics Society Meeting, Stamford - UK, 12 October 2005.

[19] G.A. Putrus, N. Jen kins, and C.B. Cooper, A Static Fault Current Limiting and Interrupting Devices,
IEE Colloquium on Fault Current Limiters - A Look at Tomorrow, London - UK, 08 June 1995.

[20] Y. Zhang, and R.A. Dougal, Determining Critical Activation Time of Inductive Fault Current Limiters in Electric Power Systems, IEEE/PES, Power Systems Conference and Exposition (PSCE), Phoenix - USA, 20-23 March 2011.

[21] X.S. Yang, Nature-Inspired Meta-Heuristic Algorithms, published by Luniver Press, UK, 2008.

[22] X.S. Yang, Firefly Algorithm for Multimodal Optimization, Stochastic Algorith ms: Foundations and Applications, SAGA, Lecture Notes in Computer Sciences, Springer, 2009, 5792: 169 178.

[23] X.S. Yang, Firefly Algorithm, Stochastic Test Functions and Design Optimisation, International Journal of Bio-Inspired Computation (IJBIC), 2010, 2(2): 78 84.

[24] A.H. Gandomi, X.S. Yang \& A.H. Alavi, Mixed Variable Structural Optimization using Firefly Algorithm, Computers \& Structures, 2011, 89(2324): $2325 \sim 2336$.

\section{Authors' Profiles}

Dr. Rabah Benabid was born in Jijel, A lgeria, in 1977. Received his B. Sc. Degree (2001), his M.Sc. degree (2007), and his Ph.D. degree (2012), all in Electrical Engineering from University of Jijel, Algeria, University of Laghouat, Algeria, and University of Sciences \& Technology Houari Boumediene (U.S.T.H.B), Algiers, Algeria, respectively. His research interests include: secondary voltage regulation, Application of evolutionary algorithms and intelligent methods in power systems, voltage stability analys is of power system, optimal reactive power dispatch, FACTS devices modeling and control, power quality, and power systemprotection.

Dr. Mohamed Zellagui was born in Constantine, Algeria, 1984. He received the engineer (Honors with first class) and M.Sc. degree in Electrical Engineering (Power System) from department of Electrical Engineering at University of Constantine, Algeria in 2007 and 2010 respectively. He is a PhD Student in Power Systems from department of Electrical Engineering at University of Batna, Algeria. Member LSP-IE research laboratory at Batna University, Algeria, During 2008-2013 he was a electrical engineering at Algerian Company of Electrical and Gas (Group Sonelgaz), Constantine, Algeria. Membership at International Association of Engineers (IAENG), and Institution of Engineering and Technology (IET), Senior Member of Universal Association of Computer and Electronics Engineers (UACEE) and International Scientific Academy of Engineering \& Technology 
(ISAET). Obtained the national award for best $\mathrm{PhD}$ student (science and technology) in the year 2012. Her research interests include power system protection, distance protection, directional overcurrent relay, optimization algorithm, renewable energy, and FACTS devices.

Prof. Abdelaziz Chaghi was born in Batna, Algeria, 1954. He received his engineer degree from the University of Oran, Algeria, in 1980, and M.Sc. from the Manchester University, UK, in 1984, and received his $\mathrm{PhD}$ from Batna University, Algeria 2004. He is currently a Professor at department of electrical engineering at University of Batna, Algeria. He is also the responsible of the research team at LSP-IE research laboratory, University of Batna. Pr. Chaghi has published more than 50 papers in reputable international journals and conferences. Pr. Chaghi research interests include power systems optimization, power system protection, renewable energy, harmonic and power quality, voltage stability, and FACTS devices.

Prof. Mohamed Boudour received the B.Sc., M.Sc. and the Ph.D. degrees in electrical engineering from the Polytechnic Institute of Algiers, Algeria in 1991, 1994 and 2004 respectively. Since January 1993, he has been with the University of Sciences and Technology Houari Boumediene (U.S.T.H.B) of Algiers, Algeria as a teacher and researcher and a Fulbright Fellowship during 2005-2006 in the University of Washington (Seattle, USA). He is now an associate professor in U.S.T.H.B. and the Director of the Industrial and Electrical Systems Research Laboratory (LSEI) since 2007. Pr. Boudour is senior member of Institute of Electrical and Electronics Engineers (IEEE), USA, and president of PES chapter in IEEE Algeria subsection. His main interests are power systems stability, security assessment, control, optimization, protection, application of intelligent and metaheuristic in electrical engineering.

How to cite this paper: Rabah Benabid, Mohamed Zellagui, Abdelaziz Chaghi, Mohamed Boudour,"Application of Firefly Algorithm for Optimal Directional Overcurrent Relays Coordination in the Presence of IFCL", International Journal of Intelligent Systems and Applications(IJISA), vol.6, no.2, pp.44-53, 2014. DOI: 10.5815/ijisa.2014.02.06 